\title{
PROLACTIN SECRETION PATTERN AMONG FEMALE FLIGHT ATTENDANTS
}

\section{MAŁGORZATA RADOWICKA, BRONISŁAWA PIETRZAK, and MIROSŁAW WIELGOŚ}

\author{
Medical University of Warsaw, Warsaw, Poland \\ First Department of Obstetrics and Gynecology
}

\begin{abstract}
Objectives: Epidemiological observations indicate that female flight attendants are exposed to some reproductive and endocrine system disturbances. The aim of the study was to determine the incidence of hyperprolactinemia among female flight attendants, and to identify factors affecting the secretion of prolactin in female flight attendants working within 1 time zone as well as on long-distance flights. Material and Methods: The cross-sectional study covered 103 women aged 23-46 years. The study group (I) was divided into 2 subgroups: subgroup Ia comprising female flight attendants flying within 1 flight zone, and subgroup Ib composed of female flight attendants working on long-distance flights. The control group (II) included women of reproductive age who sought medical assistance due to marital infertility in whom the male factor was found to be responsible for problems with conception in the course of the diagnostic process. The assessment included: age, the body mass index, menstrual cycle regularity, the length of service, the frequency of flying, the prolactin, estradiol and progesterone concentrations, and the result of endometrial biopsy. Descriptive and inferential statistics methods were used to compile the data. Results: The incidence of hyperprolactinemia in the female flight attendants (46\%) was significantly higher than in the control group (9\%), p < 0.001. Differences between subgroups Ia and Ib regarding individual concentrations were not statistically significant $(\mathrm{p}=0.425)$. Hyperprolactinemia among the female flight attendants working $\geq 15$ years is present slightly more often than in those working < 15 years: $46 \%$ vs. $45 \%$ ( $p>0.05$ ). No significant difference was revealed in the secretion of prolactin between the study participants spending $<60 \mathrm{~h} /$ month flying and those spending $\geq 60 \mathrm{~h} /$ month flying $(\mathrm{p}>0.05)$. Conclusions: Hyperprolactinemia is more common in female flight attendants than in the general population. High values of prolactin concentration in flight attendants are rarely manifested in clinical symptoms. The frequency of flying and the length of service do not affect the development of hyperprolactinemia or the mean prolactin concentration. Int J Occup Med Environ Health. 2021;34(3):351-61
\end{abstract}

Key words:

shift work, prolactin, occupational medicine, hyperprolactinemia, circadian rhythm disruption, female flight attendant

\section{INTRODUCTION}

Epidemiological observations indicate that, due to the character of the profession performed and the specificity of the working environment, female flight attendants are exposed to some reproductive and endocrine system disturbances. Their health can be adversely affected by factors such as night and shift work, cosmic radiation, changes of time zones, stress, as well as specific conditions on board the airplane [1-6]. Frequent changes of time zones and shift work cause disturbances of the cir- cadian rhythm which lead to changes in the secretion of a number of hormones, including prolactin [3]. In humans, prolactin is produced in the pituitary gland and secreted in a continuous and pulsating way. The concentration of this hormone in the plasma is the highest during sleep while its lowest values are reported during day hours [7]. The secretion of prolactin resulting in a rise in its blood serum concentration above the upper level of the laboratory norm is referred to as hyperprolactinemia.

Received: May 4, 2020. Accepted: October 15, 2020.

Corresponding author: Małgorzata Radowicka, Medical University of Warsaw, First Department of Obstetrics and Gynecology, pl. Starynkiewicza 1/3, 02-015, Warsaw, Poland (e-mail:m.radowicka@gmail.com). 
There are numerous factors responsible for hyperprolactinemia, among others, stress [8] - a factor to which flight attendants are exposed. An excessive secretion of prolactin is known to contribute to the development of numerous disturbances, manifesting themselves primarily as abnormalities of the menstrual cycle and/or infertility [8]. Findings of hitherto conducted research also indicate a significant correlation between a high prolactin concentration and the risk of breast cancer [9]. Hormonal profile disorders are suspected to be more common among flight attendants than in the general population due to the character of the profession and the specificity of the relevant working environment.

The aim of the study was to determine the incidence of hyperprolactinemia among female flight attendants, and to identify factors affecting the secretion of prolactin in female flight attendants working within 1 time zone as well as on long-distance flights.

\section{MATERIAL AND METHODS}

\section{Study design}

This cross-sectional study covered 103 Polish women aged 23-46 years. The women were examined in the Department of Gynecological Endocrinology, the Medical University of Warsaw, Poland, in 2013-2016. The approval for the study was obtained from the Ethics Board of the Medical University of Warsaw (KB/254/2013, November 12, 2013). Trade unions of LOT Polish Airlines and EUROLOT Polish Airlines were also notified about the study to be conducted. The exclusion criteria applicable to both the study and control groups included the use of hormonal drugs (including contraceptives) up to 6 months prior to the study, the use of drugs inducing the activity of hepatic enzymes which could affect the hormonal economy of the body, a history of chronic renal insufficiency and liver cirrhosis, and a diagnosis of menopause in women aged $>40$ years, according to the WHO criteria.
The trade unions gather over 500 flight attendants; 74 flight attendants responded to the invitation letter, and 43 of them were qualified for the study. The study group (I) consisted of female flight attendants flying within 1 time zone as well as those serving long-distance flights. Qualified for the study were the female flight attendants who consented to take part in the study, were of reproductive age, and worked under the night shift system. The control group (II) included 60 women of reproductive age who sought medical assistance due to marital infertility in whom the male factor was found to be responsible for problems with conception in the course of the diagnostic process.

\section{Sample collection and analysis}

The examination was performed twice: between the fourth and sixth day of the cycle (the first phase of the cycle), and 2-4 days before the expected menstrual bleeding (the second phase of the cycle). The patients were not examined directly after night shifts. The prolactin, estradiol and progesterone concentrations in the blood samples collected from the antecubital vein were assessed with an automated enzyme immunoassay. The study group was further divided into 2 subgroups: subgroup Ia $(\mathrm{N}=17)$ comprising the female flight attendants flying within 1 time zone, and subgroup Ib $(\mathrm{N}=26)$ composed of the female flight attendants working on long-distance flights. The assessment included: age, the body mass index (BMI), menstrual cycle regularity, the length of service (in years), the frequency of flying, prolactin concentration in the first phase of the cycle in the control group, the night profile of the secretion of prolactin in the study group, estradiol concentration in the first phase of the cycle, progesterone concentration in the second phase of the cycle, and the result of endometrial biopsy. The study design is presented in Figure 1.

Menstrual cycles of 25-35 days were adopted as regular. To assess the night profile of the secretion of prolactin, its 

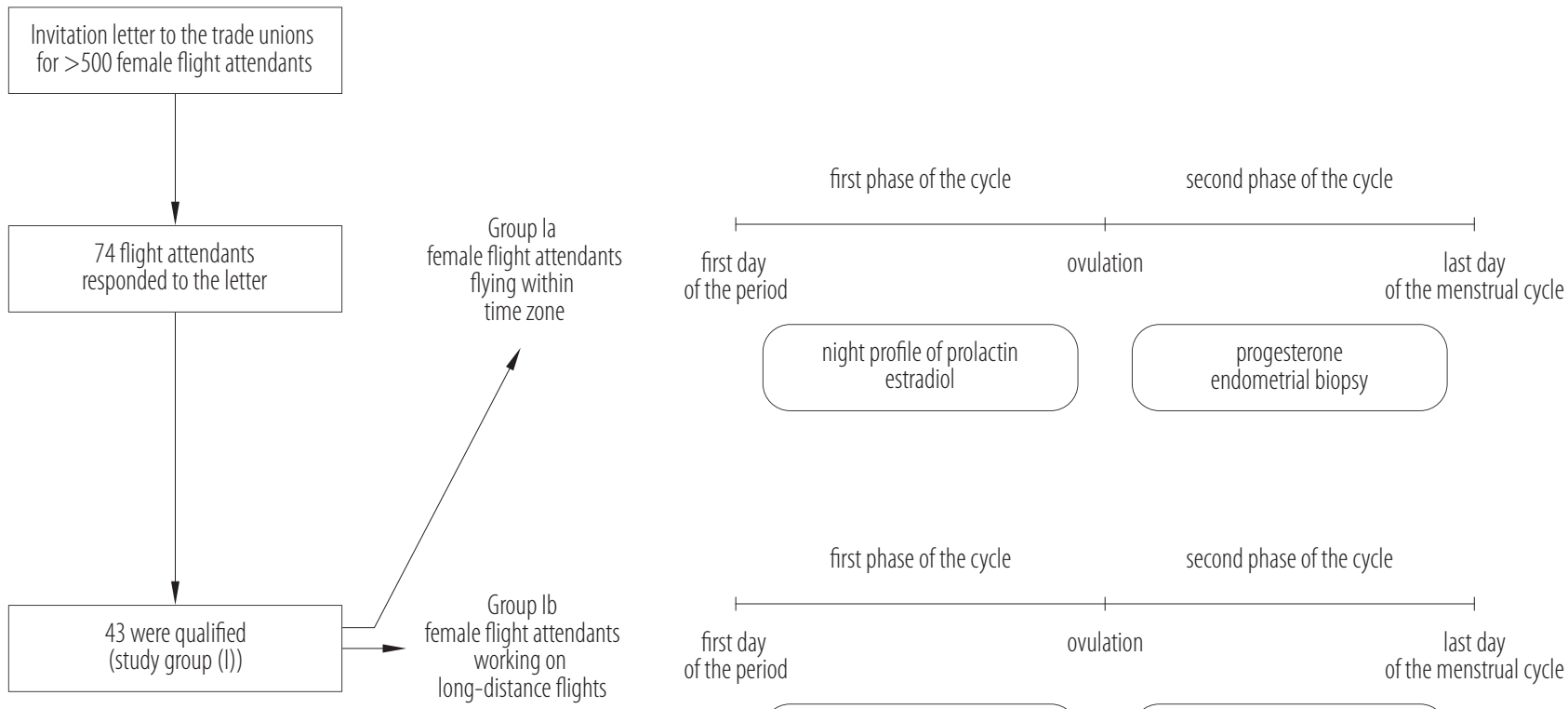

60 woman of reproductive age qualified for the study (control group (II))

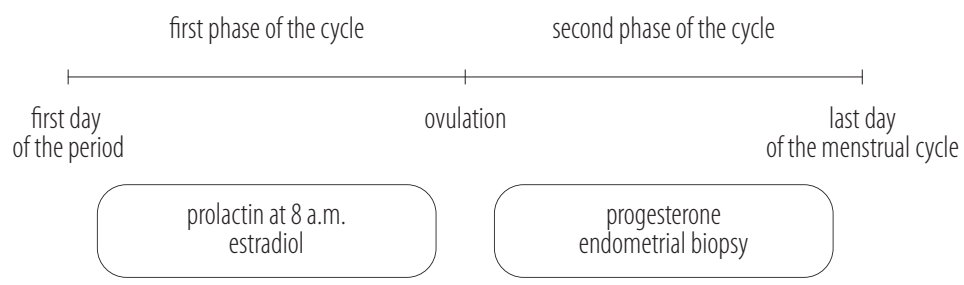

Figure 1. Design of the study on the incidence of hyperprolactinemia among female flight attendants, conducted in the Department of Gynecological Endocrinology, the Medical University of Warsaw, Poland, 2013-2016

concentration was measured at 10 p.m., 2 a.m. and 8 a.m. Endometrial biopsy was performed with the use of a disposable Pipelle probe 2-4 days before the anticipated menstruation. The histopathological images of the endometrium were classified according to the following criteria: endometrium in statu secretionis - a normal view of the endometrium, endometrium in statu proliferationis - an abnormal view, shreds of stroma, scanty material - a nondiagnostic view. The frequency of flying was expressed in terms of the number of hours spent in the air per month. With the aim of assessing the influence of the frequency of flying on the development of hormonal disturbances, the study group of the female flight attendants was divided into 2 subgroups: women working $<60 \mathrm{~h} /$ month and women working $\geq 60 \mathrm{~h} / \mathrm{month}$. With the aim of assessing the influence of the length of service on the development of hormonal disturbances, the study group of the female flight attendants was also divided into 2 subgroups: women working $<15$ years and women working $\geq 15$ years.

\section{Statistical analysis}

Descriptive and inferential statistics methods were used to compile the data. The randomness of the study sample was examined in terms of age and the length of service of 
the study participants. To this end, a test of series was applied checking the hypothesis that the way in which the women were selected could be deemed random. Knowing the order in which the subjects registered for the study, the randomness of the sample in terms of age and the length of service was confirmed. For the qualitative features, the following characteristics were calculated: the arithmetic mean (x), the median (Me), the standard deviation (SD), and the coefficient of variation ( $\mathrm{v} \%)$. The $\chi^{2}$ independence test was applied to compare the frequency of the occurrence of individual varieties of features in the study groups and subgroups. Where the expected numbers were $<5$, the Yates correction was used in the calculation of the value of the $\chi^{2}$ test. Prior to the comparison of the mean values in the study groups and subgroups, the conformity of the distributions of the analyzed measurable variables with the normal distribution was checked using the Shapiro-Wilk test.

As the distributions of the majority of the analyzed variables differed significantly from the normal distribution, the comparison of the mean values was chosen to be made using the non-parametric test, rather than the parametric test. As the samples were independent, the MannWhitney test was used to compare the mean values. To study the correlation between the measurable variables, the rank correlation coefficient was applied due to distributions being significantly different from the normal distribution. The differences between the mean values (or frequencies) were found statistically significant when the calculated value of the relevant test was equal to or higher than the critical value from the relevant tables, with the adequate number of the degrees of freedom and the probability of error of $p<0.05$.

\section{RESULTS}

\section{Characteristics of the study group and the control group}

Table 1 shows the characteristics of the study group and the control group, including the subgroups of women flying within 1 time zone and women serving long-distance flights.
The mean age of the respondents in the control group (II)

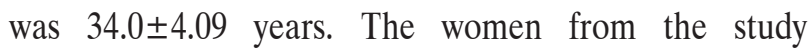
group (I) were aged 25-43 years, and the average age was $34.7 \pm 4.41$ years.

The normal BMI (18.5-24.9 $\left.\mathrm{kg} / \mathrm{m}^{2}\right)$ was reported by $81 \%$ of the female flight attendants, and underweight was present in 5\%. In the control group, the mean BMI was $22.7 \pm 3.78 \mathrm{~kg} / \mathrm{m}^{2}$.

In the study group, regular menstrual cycles were present in $70 \%$ of the participants, i.e., in 30 female flight attendants. In the control group, the frequency of the occurrence of regular menstrual cycles was $77 \%$.

The length of service in the study group ranged 6-25 years. On average, the women worked $14.3 \pm 5.06$ years. Half of the women studied worked $\geq 15$ years. The women from the study group spent $47-85 \mathrm{~h} /$ month flying, on average, $64.6 \pm 7.89 \mathrm{~h}$, while half of them spent $\geq 65 \mathrm{~h} /$ month flying.

\section{Secretion of prolactin}

The incidence of hyperprolactinemia in female flight attendants $(46 \%)$ was significantly higher than in the control group (9\%). In the study group, among 19 female flight attendants with hyperprolactinemia, clinical symptoms, i.e., galactorrhoea and irregular menstruation, were present in 8 women. The secretion of prolactin at 8 a.m. in the study group was significantly higher than in the control group: $35.4 \pm 11.8 \mathrm{ng} / \mathrm{ml}$ vs. $22.6 \pm 16.1 \mathrm{ng} / \mathrm{ml}$. A comparison of the mean concentration of prolactin at $8 \mathrm{a} . \mathrm{m}$. and the incidence of hyperprolactinemia did not reveal significant differences between the subgroup working within 1 time zone and the subgroup serving long-distance flights.

The night profile of the secretion of prolactin in the female flight attendants indicates that the mean concentration at $10 \mathrm{p} . \mathrm{m}$. amounted to $15.6 \pm 11.2 \mathrm{ng} / \mathrm{ml}$, at $2 \mathrm{a.m}$. to $46.3 \pm 48.6 \mathrm{ng} / \mathrm{ml}$, and at 8 a.m. to $35.4 \pm 11.8 \mathrm{ng} / \mathrm{ml}$. The values of prolactin concentrations at 10 p.m. ranged $3.11-73.64 \mathrm{ng} / \mathrm{ml}$, at 2 a.m. $15.72-332.23 \mathrm{ng} / \mathrm{ml}$, and at 8 a.m. $14.82-63.24 \mathrm{ng} / \mathrm{ml}$. 
Table 1. The characteristics of the study group and the control group, including the subgroups of women flying within 1 time zone and women serving long-distance flights, participating in the study on the incidence of hyperprolactinemia among female flight attendants, conducted in the Department of Gynecological Endocrinology, the Medical University of Warsaw, Poland, 2013-2016

\begin{tabular}{|c|c|c|c|c|c|c|c|c|c|c|c|c|c|c|}
\hline \multirow{4}{*}{ Variable } & \multicolumn{14}{|c|}{$\begin{array}{l}\text { Participants } \\
(\mathrm{N}=103)\end{array}$} \\
\hline & \multirow{2}{*}{\multicolumn{3}{|c|}{$\begin{array}{l}\text { control group (II) } \\
\qquad(\mathrm{N}=60)\end{array}$}} & \multicolumn{11}{|c|}{ study group I } \\
\hline & & & & \multicolumn{3}{|c|}{$\begin{array}{c}\text { total } \\
(\mathrm{N}=43)\end{array}$} & \multicolumn{4}{|c|}{$\begin{array}{c}\text { subgroup } \\
\text { Ia } \\
(\mathrm{N}=17)\end{array}$} & \multicolumn{3}{|c|}{$\begin{array}{c}\text { subgroup } \\
\text { Ib } \\
(\mathrm{N}=26)\end{array}$} & \\
\hline & $\min$. & $\max$ & $\mathrm{M} \pm \mathrm{SD}$ & $\min$. & $\max$ & $\mathrm{M} \pm \mathrm{SD}$ & $\mathrm{p}$ & $\min$. & $\max$ & $\mathrm{M} \pm \mathrm{SD}$ & $\min$. & $\max$ & $\mathrm{M} \pm \mathrm{SD}$ & $\mathrm{p}$ \\
\hline Age [years] & 23 & 46 & $34.0 \pm 4.09$ & 25 & 43 & $34.7 \pm 4.41$ & 0.203 & 26 & 43 & $34.1 \pm 4.26$ & 25 & 40 & $35.2 \pm 4.53$ & 0.219 \\
\hline BMI $\left[\mathrm{kg} / \mathrm{m}^{2}\right]$ & 17.5 & 37 & $22.7 \pm 3.78$ & 17.5 & 29.0 & $22.4 \pm 2.71$ & 0.995 & 17.5 & 28 & $21.7 \pm 2.67$ & 19 & 29 & $22.8 \pm 2.71$ & 0.28 \\
\hline Seniority [years] & & & & 6 & 25 & $14.3 \pm 5.06$ & & 6 & 18 & $13.0 \pm 4.23$ & 6 & 25 & $15.2 \pm 5.44$ & 0.084 \\
\hline $\begin{array}{l}\text { Time of work } \\
\text { in the air } \\
\text { [h/month] }\end{array}$ & & & & 47 & 85 & $64.6 \pm 7.89$ & & 47 & 70 & $59.5 \pm 6.80$ & 55 & 85 & $67.9 \pm 6.81$ & 0.001 \\
\hline
\end{tabular}

Control group (II) - 60 women of reproductive age who sought medical assistance due to marital infertility in whom the male factor was found to be responsible for problems with conception in the course of the diagnostic process; study group (I) - 43 female flight attendants; subgroup Ia - female flight attendants flying within 1 time zone; subgroup $\mathrm{Ib}$ - female flight attendants working on long-distance flights.

Bolded is $\mathrm{p}<0.001$.

In subgroup Ia, the mean concentration of prolactin at $10 \mathrm{p} . \mathrm{m}$. amounted to $13.6 \pm 5.82 \mathrm{ng} / \mathrm{ml}$, at 2 a.m. to $58.9 \pm 77.9 \mathrm{ng} / \mathrm{ml}$, and at 8 a.m. to $33.7 \pm 12.9 \mathrm{ng} / \mathrm{ml}$. In subgroup Ib, the profile of the night secretion of prolactin was as follows: at 10:00 p.m., it amounted to $16.8 \pm 13.3 \mathrm{ng} / \mathrm{ml}$, at $2 \mathrm{a} . \mathrm{m}$. to $39.1 \pm 14.9 \mathrm{ng} / \mathrm{ml}$, and at 8 a.m. to $36.3 \pm 11.2 \mathrm{ng} / \mathrm{ml}$. The differences between subgroups Ia and Ib regarding individual concentrations were not statistically significant. The curves of the night secretion of prolactin in both subgroups are shown in Figure 2.

In the study group, the mean concentration of prolactin was slightly higher in the women with irregular menstrual cycles than in the women with regular cycles: $36.1 \pm 9.81 \mathrm{ng} / \mathrm{ml} \mathrm{vs}$. $35.1 \pm 12.6 \mathrm{ng} / \mathrm{ml}$. The difference was statistically insignificant. In the control group and in subgroups Ia and Ib, statistically significant differences were not detected either. A comparison was performed of the mean secretion of prolactin at 8 a.m., and of the incidence of hyperprolactinemia depending on the length of service in the study group and in subgroups Ia and Ib. No significant correlation was found, but hyperprolactinemia among the female flight attendants working $\geq 15$ years was present slightly more often than in the subgroups working < 15 years: $46 \%$ vs. $45 \%$. Neither in the whole study group nor in subgroups Ia and $\mathrm{Ib}$ were any significant correlations found between the length of service and the secretion of prolactin at 8 a.m. The calculated rank correlation coefficients did not differ in any significant way from 0 .

The correlation was examined between the mean secretion of prolactin at $8 \mathrm{a} . \mathrm{m}$. and the incidence of hyperprolactinemia, and the number of hours which the studied female flight attendants spent flying per month. No significant difference was revealed in the secretion of prolactin between the study participants spending $<60 \mathrm{~h} /$ month flying and those spending $\geq 60 \mathrm{~h} / \mathrm{month}$ flying $(p>0.05)$. This concerns the whole study group in which the mean values of prolactin secretion amounted to $33.7 \pm 13.4 \mathrm{ng} / \mathrm{ml}$ and $36.5 \pm 10.6 \mathrm{ng} / \mathrm{ml}$, respec- 


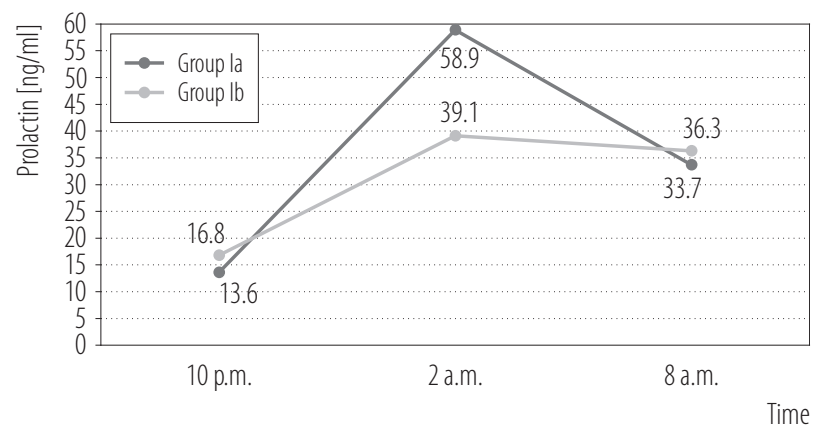

Group descriptions as in Table 1.

Figure 2. The night profile of the secretion of prolactin in groups Ia and Ib in the study on the incidence of hyperprolactinemia among female flight attendants, conducted in the Department of Gynecological Endocrinology, the Medical University of Warsaw, Poland, 2013-2016

tively, and also subgroup $\mathrm{Ib}$ in which the mean values were $40.9 \pm 13.9 \mathrm{ng} / \mathrm{ml}$ and $35.0 \pm 10.3 \mathrm{ng} / \mathrm{ml}$, respectively. As regards subgroup Ia, with the mean values of prolactin secretion of $29.8 \pm 12.0 \mathrm{ng} / \mathrm{ml}$ and $44.3 \pm 9.54 \mathrm{ng} / \mathrm{ml}$, respectively, it should be pointed out that the mean prolactin concentration was significantly higher in the subjects who spent $\geq 60 \mathrm{~h} /$ month flying than in those who spent fewer hours flying. Though this difference between the mean values did not prove statistically significant, it was fairly close to significance ( $p=0.058$ ). No statistically significant difference was found in the incidence of hyperprolactinemia between the study participants spending $<60 \mathrm{~h} /$ month flying and those spending $\geq 60 \mathrm{~h} /$ month flying $(\mathrm{p}>0.05)$.

However, it turned out that hyperprolactinemia in the subgroup spending more hours flying appeared more frequently: $50 \%$ vs. $41 \%$. In subgroup Ia, a statistically significant medium-power positive correlation was revealed between the number of hours spent flying per month by the female flight attendants and the secretion of prolactin (the rank correlation coefficient was 0.559, $\mathrm{p}<0.05$ ). Thus, it can be concluded that the more hours a month spent flying, the higher the concentration of prolactin.
A correlation of this kind was not found in the analysis of the study group and subgroup Ib.

\section{Secretion of estradiol}

The correlation was examined between the secretion of estradiol and the number of hours spent flying. Both in the study group as a whole and in subgroups Ia and Ib, the rank correlation coefficients did not differ in any significant way from 0 . The analysis of the correlation between the secretion of estradiol and the length of service revealed that both in the study group as a whole and in subgroup $\mathrm{Ib}$, there was a significant and moderately strong positive correlation between these 2 factors. Thus, the longer the length of service, the higher the concentration of estradiol. This correlation was not observed in subgroup Ia where the rank correlation coefficient did not differ significantly from 0 . In the study group as whole, a significant and moderately strong positive correlation was revealed between the concentration of estradiol in the study participants and the secretion of prolactin at 10 p.m. (the rank correlation coefficient was $0.358, \mathrm{p}<0.05$ ). Simultaneously, no statistically significant correlations were found in subgroup Ia between the concentration of estradiol and the secretion of prolactin at 2 a.m. and at 8 a.m. The calculated rank correlation coefficients did not differ significantly from 0 .

\section{Secretion of progesterone}

A significant difference was revealed in the concentration of progesterone between the study group and the control group, subgroup Ia and the control group $(5.93 \mathrm{ng} / \mathrm{ml}$ vs. $10.3 \mathrm{ng} / \mathrm{ml}, \mathrm{p}<0.01)$, as well as subgroup Ib and the control group (5.09 ng/ml vs. $10.3 \mathrm{ng} / \mathrm{ml}, \mathrm{p}<0.001)$. The progesterone concentration of $>10 \mathrm{ng} / \mathrm{ml}$ in the second phase of the cycle, providing evidence for the occurrence of ovulation, was present in 6 flight attendants (15\%). A significant difference $(\mathrm{p}<0.001)$ was found between the study group and the control group. Progesterone concentrations 
Table 2. The concentrations of the hormones in the study group and the control group, including the subgroups of women flying within 1 time zone and women serving long-distance flights, participating in the study on the incidence of hyperprolactinemia among female flight attendants, conducted in the Department of Gynecological Endocrinology, the Medical University of Warsaw, Poland, 2013-2016

\begin{tabular}{|c|c|c|c|c|c|c|c|c|c|c|c|c|c|c|}
\hline \multirow{4}{*}{ Hormone } & \multicolumn{14}{|c|}{$\begin{array}{l}\text { Participants } \\
(\mathrm{N}=103)\end{array}$} \\
\hline & \multirow{2}{*}{\multicolumn{3}{|c|}{$\begin{array}{l}\text { control group (II) } \\
\quad(\mathrm{N}=60)\end{array}$}} & \multicolumn{11}{|c|}{ study group I } \\
\hline & & & & \multicolumn{3}{|c|}{$\begin{array}{c}\text { total } \\
(\mathrm{N}=43)\end{array}$} & \multicolumn{4}{|c|}{$\begin{array}{c}\text { subgroup } \\
\text { Ia } \\
(\mathrm{N}=17)\end{array}$} & \multicolumn{3}{|c|}{$\begin{array}{c}\text { subgroup } \\
\mathrm{Ib} \\
(\mathrm{N}=26)\end{array}$} & \\
\hline & $\min$. & $\max$ & $\mathrm{M} \pm \mathrm{SD}$ & $\min$. & $\max$ & $\mathrm{M} \pm \mathrm{SD}$ & $\mathrm{p}$ & $\min$. & $\max$ & $\mathrm{M} \pm \mathrm{SD}$ & $\min$. & $\max$ & $\mathrm{M} \pm \mathrm{SD}$ & $\mathrm{p}$ \\
\hline $\begin{array}{l}\text { Prolactin [ng/ml] } \\
\text { (at } 8 \text { a.m.) }\end{array}$ & 5.56 & 123.9 & $22.6 \pm 16.1$ & 14.82 & 63.24 & $35.4 \pm 11.8$ & $<0.001$ & 15.97 & 56.76 & $33.7 \pm 12.9$ & 14.82 & 63.24 & $36.3 \pm 11.2$ & 0.425 \\
\hline Estradiol $[\mathrm{ng} / \mathrm{ml}]$ & 10 & 303 & $47 \pm 39$ & 10 & 139 & $49.4 \pm 27.2$ & 0.368 & 10 & 107 & $45.8 \pm 24.1$ & 19 & 139 & $51.6 \pm 29.1$ & 0.635 \\
\hline $\begin{array}{l}\text { Progesterone } \\
{[\mathrm{ng} / \mathrm{ml}]}\end{array}$ & 1.33 & 23.3 & $10.3 \pm 4.91$ & 0.29 & 16.89 & $5.44 \pm 3.64$ & $<0.001$ & 1.0 & 16.89 & $5.93 \pm 4.17$ & 0.29 & 11.15 & $5.09 \pm 3.28$ & 0.679 \\
\hline
\end{tabular}

Group descriptions as in Table 1.

Bolded are $\mathrm{p}<0.001$.

of $>10 \mathrm{ng} / \mathrm{ml}$ were seen more frequently in the control group than in the study group: $50 \%$ vs. $15 \%$.

The assessment of the secretion of progesterone did not reveal any significant correlation between the mean concentration of this hormone in the women with $\geq 15$ years of service and those with $<15$ years of service. A comparison of the correlation between the mean concentration of progesterone and the frequency of flying did not reveal any significant difference either. The progesterone concentrations in the study participants spending $<60 \mathrm{~h} /$ month flying and those spending $\geq 60 \mathrm{~h} / \mathrm{month}$ flying were similar: $6.08 \pm 4.24 \mathrm{ng} / \mathrm{ml}$ and $5.03 \pm 3.25 \mathrm{ng} / \mathrm{ml}$.

Table 2 shows the prolactin, estradiol and progesterone concentrations in the individual groups and subgroups.

\section{Analysis of endometrial biopsy}

The frequency of the occurrence of histopathological diagnoses of endometrial biopsy in the individual groups and subgroups is given in Figure 3. A significant difference was found in the frequency of the occurrence of normal and abnormal results of the scratch biopsy of the endome- trium. Abnormal biopsy results were confirmed to be more commonly observed in the study group than in the control group: $23 \%$ vs. $3 \%$, as well as in subgroup Ia than in the control group: $31 \%$ vs. $3 \%$.

The correlation between the mean prolactin concentration and the result of the histopathological examination of the endometrium was assessed. The presence of such a correlation was revealed neither in the study group nor in the women serving long-distance flights. Simultaneously, in the women working within 1 time zone, the mean prolactin concentration was found to be significantly higher in the subjects with an abnormal result of the scratch biopsy of the endometrium in comparison to the women with a normal view of the endometrium: $35.6 \pm 3.95 \mathrm{ng} / \mathrm{ml}$ vs. $33.4 \pm 13.9 \mathrm{ng} / \mathrm{ml}(\mathrm{p}<0.05)$.

A comparison was made between the occurrence of normal and abnormal results of the aspiration biopsy in relation to the length of service in the study group, and in subgroups Ia and Ib. No significant difference was found but abnormal biopsy results were observed slightly more frequently among the flight attendants with a longer length 
a)

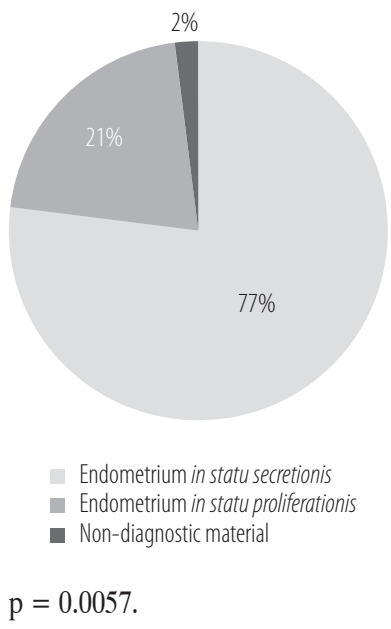

b)

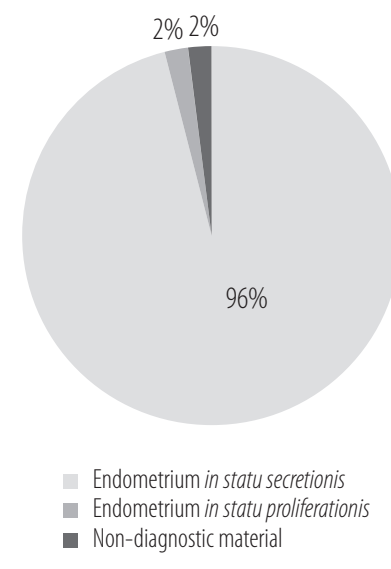

Figure 3. Images of the endometrium in a) the study group and b) the control group, in the study on the incidence of hyperprolactinemia among female flight attendants, conducted in the Department of Gynecological Endocrinology, the Medical University of Warsaw, Poland, 2013-2016

of service: $14 \%$ vs. $10 \%$. The frequency of the occurrence of normal and abnormal results of the aspiration biopsy of the endometrium was examined in relation to the frequency of flying in the study group and in subgroups Ia and Ib. No significant differences were found. However, it turned out that abnormal biopsy results were more frequently observed in the flight attendants spending $>60 \mathrm{~h} /$ month flying: $32 \%$ vs. $11 \%$.

A comparison was made of the regularity of the menstrual cycle and the length of service in the study group and in subgroups Ia and Ib. No significant difference was found but irregular menstrual cycles were more frequently observed in the study participants with a shorter length of service.

The correlation was also examined between the regularity of the menstrual cycle and the frequency of flying in the study group and in subgroups Ia and Ib. No significant difference was revealed in the frequency of the occurrence of regular and irregular menstrual cycles in each of the groups and subgroups examined. Irregular menstrual cycles were found to be slightly more common in the women spending $\geq 60 \mathrm{~h} /$ month flying: $32 \%$ vs. $28 \%$.

\section{DISCUSSION}

Hyperprolactinemia is a hormonal disorder diagnosed in $0.4-3 \%$ of healthy adults [8]. In the female flight attendants studied, it was observed definitely more frequently, i.e., in as many as $45 \%$ of the study participants. The clinical symptoms of hypeprolactinemia in the form of irregular menstruations or galactorrhoea were observed only in 8 of the women. The high concentrations of prolactin inadequate to the clinical symptoms arouse a suspicion of the presence of macroprolactinemia. Macroprolactin (big-big prolactin) is a large complex of monomeric prolactin and immunoglobulin $\mathrm{G}$, leading to increased total prolactin levels [10]. Due to the large size of the particle (>150 kDa), macroprolactin has a more difficult access to tissue receptors and, consequently, has little biological effect while maintaining full immunoreactivity [11]. According to literature, macroprolactin occurs in 15-35\% of the cases of idiopathic hyperprolactinemia [12]. In the absence of clinical symptoms, and upon excluding the presence of a tumor of the hypophysis and hepatic diseases, any treatment of a high prolactin concentration is considered to be groundless [13].

The fact that this study revealed a frequent occurrence of hyperprolactinemia in female flight attendants signifies that they are in the high-risk group as regards breast cancer. The biochemical mechanism responsible for the participation of prolactin in the cancerogenic process is not yet fully known although it has been found that the increased proliferation of the mammary gland cells is the effect of the activation of their prolactin receptor. Research findings seem to suggest that the disturbance in the circadian rhythm associated with night work can lead, among others, to decreasing the concentration (secretion) of prolactin at night [13]. The results of the few studies in this field have indicated that night work does not contribute to increasing prolactin concentrations, and that this hormone does not play a significant role in the pathogenesis of breast cancer in people working at night [4]. 
The findings of this study did not show that the length of service or the frequency of flying had any significant influence on the secretion of prolactin and the occurrence of hyperprolactinemia. What was, however, observed was that the hyperprolactinemia occurred much more frequently among the women spending $\geq 60 \mathrm{~h} /$ month flying than in those spending $<60 \mathrm{~h} /$ month flying: $50 \%$ vs. $41 \%$. Yet, the difference was not statistically significant. The assessment of the prolactin secretion curve revealed that the mean prolactin concentration at 8 a.m. was $35.4 \mathrm{ng} / \mathrm{ml}$ which signifies that it satisfies the criterion of diagnosing hyperprolactinemia. The comparison of the 2 subgroups (Ia and Ib) showed that the female flight attendants flying within 1 time zone had a substantially higher prolactin concentration at 10 p.m. than those serving long-distance flights, the difference not being statistically significant. The character of work of the women flying within 1 time zone involved more frequent takeoffs and landings, and more frequent night flights. It can thus be presumed that the increased concentration of prolactin in flight attendants is not caused by shift work but by the character of work generating more stressogenic situations.

The inefficiency of corpus luteum and the number of anovulatory cycles are known to decrease with age. Vekemans and Robyn [14] observed that the older the woman, the lower the mean prolactin concentration in blood serum. The authors confirmed that higher concentrations of estradiol, if not offset by progesterone concentrations, intensify the prolactin secretion by the hypophysis [14]. The study participants involved in the present study were relatively young (the mean age was 35 years). The mean progesterone concentration in the study group was not high, amounting to $5.44 \mathrm{ng} / \mathrm{ml}$ while that of estradiol was $49.4 \mathrm{ng} / \mathrm{ml}$. The progesterone concentration of $>10 \mathrm{ng} / \mathrm{ml}$ in the second phase of the cycle, providing evidence for the occurrence of ovulation, was present in only 6 flight attendants (15\%).
In the study group of flight attendants, a positive correlation between estradiol concentration and prolactin concentration was observed at 10 p.m. A positive effect of estradiol on the secretion of prolactin at 10 p.m. in the control group of women with regular menstruation was also reported by Szlendak-Sauer [15] in the study describing the prolactin profile in patients with menstrual disturbances. Veldhuis et al. [16] showed that estradiol induced a 2- or 3-fold increase in the amplitude of prolactin secretion without affecting the frequency of pulses [16]. Nor did it affect the metabolic transformations of hormone particles.

An analysis of the correlation between estradiol secretion and the length of service revealed that, in the whole group, there was a statistically significant and moderately strong positive correlation; thus, the longer the length of service, the higher the concentration of estradiol. A higher concentration of estradiol in shift-working women was also reported by Bracci et al. [17]. It thus seems possible that what contributes to the increased incidence of hyperprolactinemia in female flight attendants is the estradiol concentration increasing with the length of service. In consequence, further epidemiological research seems necessary on larger groups of flight attendants.

Prolactin is known to physiologically stimulate the secretion of the luteotropic hormone and the production of progesterone by corpus luteum in the luteal phase of the menstrual cycle. High concentrations of prolactin hamper folliculogenesis and the selection of the follicle dominant in the ovary, as well as the normal decidual reaction of the endometrium [18]. Abnormal biopsy results testifying to the absence of a normal decidual reaction were observed more frequently in the study group than in the control group. A more frequent occurrence of abnormal endometrial biopsy results was also observed in the flight attendants working $\geq 15$ years and those spending $\geq 60 \mathrm{~h} /$ month flying. It can be supposed that the obtained results provide evidence for a more frequent occurrence of anovulatory cycles in flight attendants, which 
is confirmed by the average low progesterone concentrations in the second phase of the cycle.

This study is the first attempt at assessing the role of the prolactin secretion pattern among flight attendants. The prolactin concentration revealed in the night profile of its secretion adds to the accuracy of the research. In addition, the study compares the secretion of prolactin with the secretion of other hormones, which has not been given extensive attention so far. These strengths of the study have to be seen against its limitations resulting from the non-inclusion of data on parity, the number of pregnancies, cigarette smoking, as well as chronic stress, which are also seen as being associated with prolactin secretion. A larger group would also be necessary to ensure a representative distribution of the population to allow for the results to be generalized and transferred.

\section{CONCLUSIONS}

Hyperprolactinemia is more common in female flight attendants than in the general population. High values of prolactin concentration in flight attendants are rarely manifested in clinical symptoms. The frequency of flying and the length of service do not affect the development of hyperprolactinemia or the mean prolactin concentration. Hyperprolactinemia occurs as frequently in women working within 1 time zone as in those serving long-distance flights. Further research is necessary to qualitatively assess the effect of the increased prolactin concentration.

\section{REFERENCES}

1. Yang Y, Zhang W, Chan A, Li C, He X, Cui L, et al. An epidemiological study of reproductive health in female civil aviation employees. Aviat Space Environ Med. 2013;84(6):625-9, https://doi.org/10.3357/asem.3499.2013.

2. Grajewski B, Whelan EA, Lawson CC, Hein MJ, Waters MA, Anderson JL, et al. Miscarriage among flight attendatns. Epidemiology. 2015;26(2):192-203, https://doi.org/10.1097/EDE. 0000000000000225 .
3. Sigurdson AJ, Ron E. Cosmic radiation exposure and cancer risk among flight crew. Cancer Invest. 2004;22(5):743-61, https://doi.org/10.1081/cnv-200032767.

4. Bukowska A, Pepłońska B. Night shift work and prolactin as a breast cancer risk factor. Med Pr. 2013;64(2):245-57.

5. Bukowska A, Sobala W, Pepłońska B. Rotating night shift work, sleep quality, selected lifestyle factors and prolactin concentration in nurses and midwives. Chronobiol Int. 2015;32(3): 318-26, https://doi.org/10.3109/07420528.2014.975353.

6. Shechter A, Boivin DB. Sleep, Hormones, and Circadian Rhythms throughout the Menstrual Cycle in Healthy Women and Women with Premenstrual Dysphoric Disorder. Int J Endocrinol. 2010;2010 special issue, https://doi. org/10.1155/2010/259345.

7. Morris CJ, Aeschbach D, Scheer FA. Circadian system, sleep and endocrinology. Mol Cell Endocrinol. 2012;349(1): 91-104.

8. Majumdar A, Mangal NS. Hyperprolactinemia. J Hum Reprod Sci. 2013;6(3):168-75, https://doi.org/10.4103/0974-1208.121400.

9. Tworoger SS, Eliassen AH, Zhang X, Qian J, Sluss PM, Rosner BA, et al. A 20-year prospective study of plasma prolactin as a risk marker of breast cancer development. Cancer Res. 2013;73(15):4810-9, https://doi.org/10.1158/0008-5472. CAN-13-0665.

10. Sherazi NA, Baig MZ, Khan AH. Frequency of Macroprolactin in Hyperprolactinemia. J Coll Physicians Surg Pak. 2018;28(2):93-5, https://doi.org/10.29271/jcpsp.2018.02.93.

11. Vaishya R, Gupta R, Arora S. Macroprolactin; A Frequent Cause of Misdiagnosed Hyperprolactinemia in Clinical Practice. J Reprod Infertil. 2010;11(3):161-7.

12. Kasum M, Oreskovic S, Zec I, Jezek D, Tomic V, Gall V, et al. Macroprolactinemia: new insights in hyperprolactinemia. Biochem Med. 2012;22(2):171-9.

13. Suliman AM, Smith TP, Gibney J, McKenna TJ. Frequent mis-diagnosis and mismanagement of hyperprolactinemic patients before the introduction of macroprolactin screening application of a new strict laboratory definition of macroprolactinemia. Clin Chem. 2003;49(9):1504-9. 
14. Vekemans M, Robyn C. Influence of age on serum prolactin levels in women and men. Br Med J. 1975;4(5999):738-9, https://doi.org/10.1136/bmj.4.5999.738.

15. Szlendak-Sauer K. Profil nocny wydzielania prolaktyny u kobiet z zaburzeniami miesiączkowania a obraz endometrium. PhD thesis. Warsaw: Medical University of Warsaw; 2007. Polish.

16. Veldhuis JD, Evans WS, Stumpf PG. Mechanisms that subserve estradiol's induction of increased prolactin concentration: evidence of amplitude modulation of spontaneous prolactin secretory bursts. Am J Obstet Gynecol. 1989; 161(5):1149-58.

17. Bracci, M, Manzella N, Copertaro A, Staffolani S, Strafella E, Barbaresi M, et al. Rotating-shift nurses after a day off: peripheral clock gene expression, urinary melatonin, and serum 17- $\beta$-estradiol levels. Scand J Work Environ Health. 2014;40(5):295-304, https://doi.org/10.5271/sjweh.3414.

18. Dexeus S, Barri PN. Hyperprolactinemia: an inductor of neoplastic changes in endometrium? A report of two cases. Gynecol Endocrinol. 1998;12(4):271-5.

This work is available in Open Access model and licensed under a Creative Commons Attribution-NonCommercial 3.0 Poland License - http://creativecommons.org/ licenses/by-nc/3.0/pl/deed.en. 